\title{
Why do Polish medical students resign from pursuing surgical careers? A survey study
}

\author{
Authors' Contribution: \\ A-Study Design \\ B-Data Collection \\ C-Statistical Analysis \\ D-Data Interpretation \\ E-Manuscript Preparation \\ C-Funds Collection
}

\author{
Urszula Skorus ${ }^{1 \mathrm{ABCDEF}}$, Izabela A. Karpińskaa ${ }^{1 \mathrm{ABDEF}}$, Anna Kominko ${ }^{1 \mathrm{ABEF}}$, Michał Romaniszyn ${ }^{2 \mathrm{ACDE}}$
}

'SSC of Surgical Skills, Department of Medical Didactics, Jagiellonian University Medical College, Poland

${ }^{2}$ Department of Medical Didactics, Jagiellonian University Medical College, Poland; Head: Crzegorz Cebula PhD

Article history: Received: 27.11.2019 Accepted: 07.02.2020 Published: 07.02.2020

ABSTRACT: $\quad$ Background: In recentyears, the interest of Polish medical students in choosing a career in surgical subspecialties has been declining. In the face of a growing demand for surgical procedures it seems essential to find the reasons responsible for that situation.

Aim: The aim of the study was to evaluate the level of interest in pursuing surgical careers among Polish medical students and to identify factors that may influence their decision.

\begin{abstract}
Material and methods: An anonymous questionnaire was distributed electronically among students from 11 different Polish medical universities.

Results: We surveyed 595 individuals (190 male and 405 female). $48 \%$ of them declared interest in choosing surgical subspecialty as a career. The percentage of students who considered it before medical school was higher and reached almost $65 \%$. Slight or no interest in surgery as a field of study $(\mathrm{OR}=20.6)$, self-assessment of surgical predispositions as unsatisfactory $(O R=14.3)$, feeling unable to enter and accomplish surgical specialty $(O R=5.2)$, being discouraged by the partner $(O R=3.4)$, negative past experience with the surgical environment $(O R=3.2)$, not having a surgeon as a mentor $(O R=2.6)$, no authorship of journal articles or congress presentations $(O R=1.9)$ and first contact with the operating theatre $>2$ nd year of study $(O R=1.9)$ were found to be the independent risk factors of abandoning a surgical career.
\end{abstract}

Conclusions: Most medical students are interested in pursuing a surgical specialty at some time during their education. However, being discouraged by lifestyle issues, surgical training quality or experiencing gender discrimination, they often resign from such a career path.

KEYWORDS: $\quad$ career choice, medical students, motivation, surgery, undergraduate medical education

The research comprises a survey study assessing the level of interest of Polish students in pursuing surgical careers, including the analysis of factors discouraging from choosing such a career path.

\section{INTRODUCTION}

The practice of surgery presents as an unique opportunity to combine leadership and decision-making skills with intellectual and technical challenges [1]. That is why general surgery has been regarded traditionally as a popular and competitive specialty [2]. However, the attractiveness of a surgical career has been called into question by the current generation of students. Over the last two decades, there has been reported a steady decrease in the percentage of graduates entering surgical training. This trend was observed in the United States where the percentage of medical students ranking general surgery programs as their first choice decreased from $10.7 \%$ in 1984 to less than 5\% in 2002 and 4.5\% in 2018, and also in Canada where surgical specialties have had a reduction in applications ranking surgical programs as the first choice from $24.7 \%$ in 1998 to $21.7 \%$ in 2006 and $17.2 \%$ in 2016 [3-4]. The same situation occurs in Western Europe. Interest in a surgical career in the United Kingdom peaked in 2005 , with $22.3 \%$ of the graduating medical student class matching in general surgery, whereas in 2015 there were only $14.2 \%$ [5-6]. The diminishing number of general surgeons is a disturbing issue also among the Polish society. Based on official statistics as for October 2019, there are 8,970 general surgeons in Poland with a mean age 55.7 years $[7,8]$. The majority (more than $64 \%$ ) of them is above 50 years of age [8]. Most importantly, the number of professionally active general surgeons is expected to decrease significantly in the next 20 years [9]. With the growing old age dependency ratio across Europe, the workload on surgical services will increase [10]. The declining interest in general surgery along with an increasing demand for surgical procedures may certainly lead to a shortage of specialized surgeons in the future [11-12]. Effort has been made to understand why medical students have deterred from choosing a surgical carrier. Recently, studies from different countries have suggested that the issue is multifactorial, but lifestyle factors have surfaced as the primary issues contributing to students' lack of interest in surgery [2,13-14]. Most of the data derive from foreign works, so they may not be directly relevant to Poland. Despite many differences in both undergraduate and postgraduate training, there is a widespread perception that a similar trend exists in our country.

The main objective of this questionnaire study was to evaluate the level of interest in a surgical training among medical students in Poland as well as to identify the determinants influencing their decisions. A deeper understanding of discouraging factors and students' requirements on surgical training is mandatory to counteract a future shortage of specialized surgeons and would help to recruit the most promising candidates for a surgical residency [15].

\section{MATERIALS AND METHODS}

The online survey was distributed to medical students from 11 different Polish medical universities in January of 2019. The question- 


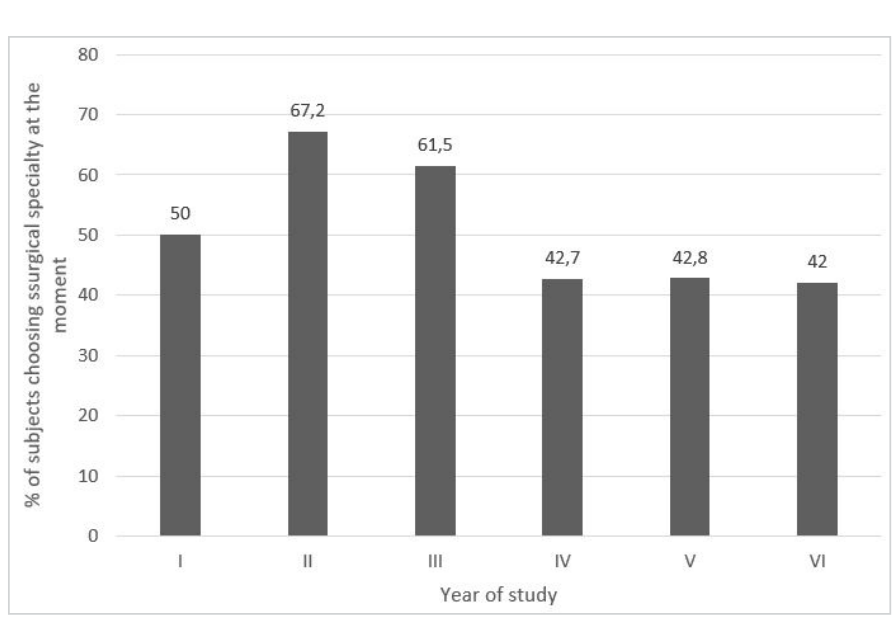

Fig. 1. Percentage of students choosing a surgical specialty as a future career in relation to the year of study.

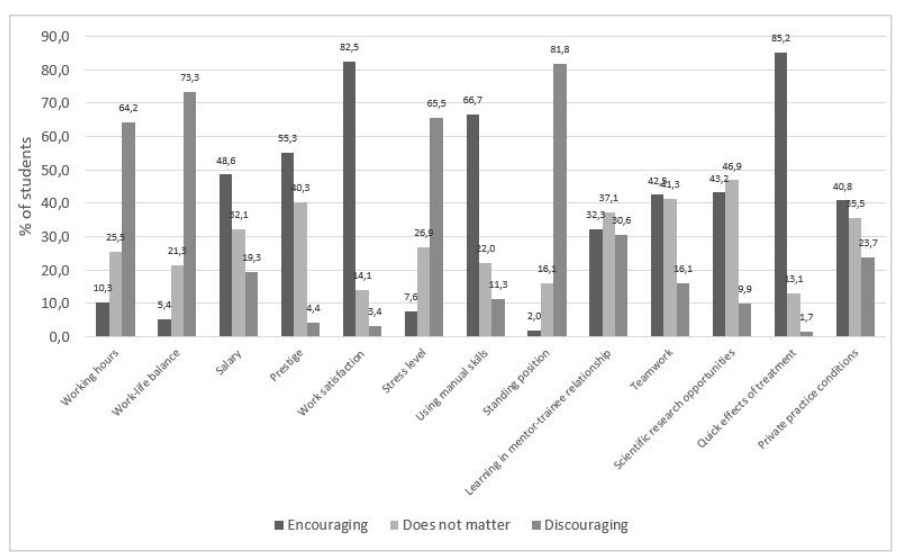

Fig. 2. Encouraging or discouraging impact of surgeons' lifestyle issues and way of working-students' opinion.

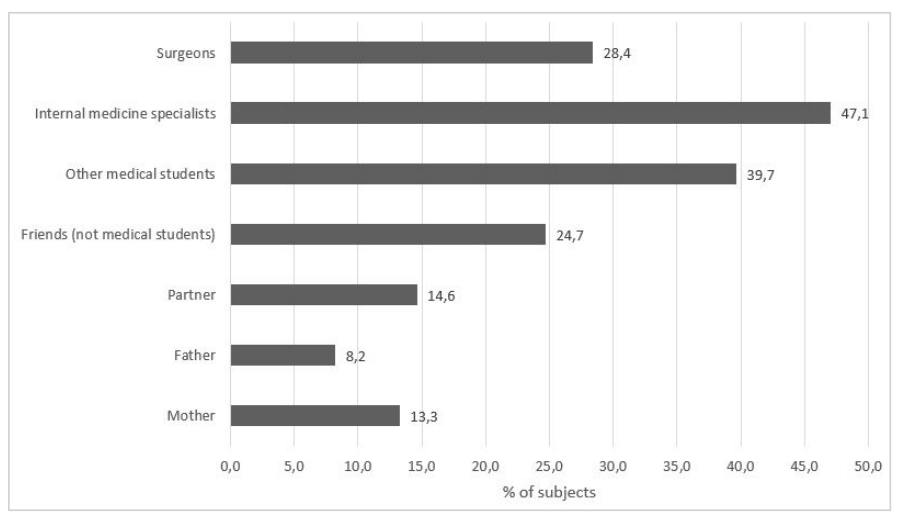

Fig. 3. Percentage of subjects discouraged from pursuing surgical careers by different groups of authorities.

naire was created based on the literature review and consultations with medical students, surgical residents, surgeons and academic teachers. It consisted of 34 items grouped in 9 categories (demographics, grades and scientific achievements, interest in pursuing surgical career, lifestyle issues, way of working, surgical education, experience with the surgical environment, predispositions and the opinions of others) (Tab. I.).

Students were asked to choose the type of specialty they would select at the moment (surgical vs medical). Surgical specialties included general, cardiac, thoracic, pediatric, maxillofacial and plastic surgery, neurosurgery, gynecology and obstetrics, otolar- yngology and orthopedics. We than compared answers between two groups of students (choosing surgical or medical specialty).

We also extracted the group of students who had considered surgical specialty in the past but changed their mind during the study period. To identify the factors which discouraged students primarily interested in surgery from pursuing a surgical career, the logistic regression analysis was performed.

The Ethics Committee of the Jagiellonian University approved the study.

\section{STATISTICAL ANALYSIS}

Data were analyzed using the Statistica 13.3 software. Categorical variables were showed as numbers with percentages. Continuous variables were described as a median with a range. To confirm the normality of distribution of continuous variables we used the Shapiro-Wilk and the Kolmogorov-Smirnov tests, with the Lilliefors correction. For comparison of independent continuous variables, we used the Mann-Whitney U test. Pearson's chi2 was used for testing independence in contingency tables. Statistical significance was defined as a $\mathrm{p} \leq 0.05$. The impact of risk factors on resignation from pursuing a surgical specialty was assessed using the logistic regression method. Youden's index was used for determining the appropriate cutoff points while converting continuous to categorical variables. Firstly, univariate analysis was performed. Then, forward stepwise multivariate logistic regression was applied to identify independent risk factors of resignation from pursuing a surgical specialty. The entry criterion for the model was $\mathrm{p} \leq 0.1$ in the univariate analysis. The fit of the logistic models was assessed using the Hosmer-Lemeshow test, and considered good with $\mathrm{p}>0.05$.

\section{RESULTS}

\section{Demographics}

We included 595 individuals, 405 (68\%) female and 190 (32\%) male. The median age was 23 ranging from $18-30$. The survey was completed by 125 (21\%) students from the Jagiellonian University Medical College, 90 (15\%) students from the Medical University of Lodz and 84 (14.1\%) from the Medical University of Silesia. Students from the remaining eight universities accounted together for $50 \%$ (296) of the surveyed. Most of them were 4th and 5 th year students (34\% and $26 \%$, respectively), but students at every grade were included. Detailed demographic data is displayed in Tab. II.

\section{Comparison between students choosing a surgical and non- surgical specialty}

From all subjects, 286 (48\%) declared an interest in pursuing a surgical career after finishing medical school, while 309 (52\%) chose a non-surgical specialty. The students who decided for a surgical specialty were more likely to be male $(57 \%$ vs $43 \%, \mathrm{p}=0.002)$.

Only in 2nd and 3rd year students, surgery was chosen by a significantly higher percentage of individuals (2nd year: 67\% vs 33\%, $\mathrm{p}=0.002$; 3rd year: $62 \%$ vs $38 \%, \mathrm{p}=0.005)$. Among 4 th, 5 th and 6 th year students more frequently medical specialties were chosen but 
Tab. I. Survey algorithm. Nine categories derived from 34 items.

$\begin{array}{ll}\text { 1. Demographics } & \text { 1. Age } \\ & \text { 2. Gender } \\ & \text { 3. Year of study } \\ \text { 2. Grades and Scientific Achievements } & \text { 1. Grade point average } \\ & \text { 2. Authorship of journal articles or congress presentations }\end{array}$

3. Interest in pursuing
a surgical career

1. Considering pursuing a surgical career in the past

2. Decision at the moment
1. Working hours
2. Work-life balance
3. Salary
4. Prestige
5. Work satisfaction
6. Stress level

4. Surgeons' lifestyle issues (encouraging/

1. Using manual skills

2. Standing position

3. Learning in a mentor-trainee relationship

5. Surgeons' way of working (encouraging/ discouraging impact)

4. Teamwork

5. Scientific research opportunities

6. Quick effects of treatment

7. Private practice conditions

1. Opinion on surgical education quality

2. Interest in surgery as a field of study

3. Forms of surgical training contained within curriculum:

-Suturing on a training kit or animal tissues

- Training on a laparoscopic simulator

- Wound management course

Fractures management course

- Assisting at surgical operations

4. Access to extracurricular activities:

- Taking part in surgical duties

Practical training in student scientific groups

6. Surgical education

-Workshops organized by students societies or taking place at medical conferences

- Assisting at surgical operations

5. Procedures performed during surgical rotations or extracurricular activities:

- Dressing change

Removing stitches

- Surgical drains removal

Urinary catheterization

- Central line placement

- Cannulation of peripheral veins

-Wound suturing

Gastric tube placement

- Tracheal intubation

Fracture management

7. Experience with the surgical environment

1. Time of first contact with the operating theatre

2. Surgeon in the family

3. Having a mentor who is a surgeon

4. Positive/negative contact with surgical environment in the past

1. Self-assessment of surgical predispositions

8. Surgical predispositions

2. Self-assessment of ability to enter and accomplish surgical residency

3. Self-assessment of difficulties in contact with surgical patients

1. Gender discrimination

2. Being discouraged by others:

- Mother

- Father

9. Opinions of others

- Partner

- Friends (not medical students)

- Other medical students

- Internal medicine specialist

- Surgeons 
Tab. II. Comparison of demographic factors, grades, scientific achievements and self- assessment of surgical predispositions between groups of students based on career choice.

\begin{tabular}{|c|c|c|c|c|}
\hline & $\begin{array}{l}\text { ALL SUBJECTS } \\
\mathrm{N}=595\end{array}$ & $\begin{array}{l}\text { CHOOSING A SURGICAL SPECIALTY } \\
\mathrm{N}=\mathbf{2 8 6}(\mathbf{4 8 . 0 7 \% )}\end{array}$ & $\begin{array}{l}\text { CHOOSING A MEDICAL SPECIALTY } \\
\mathrm{N}=309(51.93 \%)\end{array}$ & PVALUE \\
\hline Median age & $23(18-30)$ & $23(18-30)$ & $23(19-28)$ & 0.181 \\
\hline Female & $405(68.1)$ & $177(43.7)$ & $228(56.3)$ & 0.002 \\
\hline Male & $190(31$ C.9) & $109(57.4)$ & $81(42.6)$ & \\
\hline \multicolumn{5}{|l|}{ Year of study: } \\
\hline I & $14(2.4)$ & $7(50.0)$ & $7(50.0)$ & 0.884 \\
\hline II & $58(9.8)$ & $39(67.2)$ & $19(32.8)$ & 0.002 \\
\hline III & $91(15.3)$ & $56(61.5)$ & $35(38.5)$ & 0.005 \\
\hline IV & $199(33.5)$ & $85(42.7)$ & $114(57.3)$ & 0.064 \\
\hline V & $152(25.6)$ & $65(42.8)$ & $87(57.24)$ & 0.129 \\
\hline VI & $81(13.6)$ & $34(41.98)$ & $47(58.02)$ & 0.238 \\
\hline \multicolumn{5}{|l|}{ Grade point average ${ }^{*}:$} \\
\hline$<3.0$ & $5(0.8)$ & $2(0.7)$ & $3(1.0)$ & 0.717 \\
\hline $3.0-3.4$ & $44(7.4)$ & $25(8.7)$ & $19(6.2)$ & 0.227 \\
\hline $3.5-3.9$ & $163(27.4)$ & $75(26.2)$ & $88(28.5)$ & 0.538 \\
\hline $4.0-4.4$ & $240(40.3)$ & $120(42.0)$ & $120(38.8)$ & 0.438 \\
\hline $4.5-5.0$ & $128(21.5)$ & $57(19.9)$ & $71(22.9)$ & 0.366 \\
\hline Authorship of journal articles or congress presentations & $290(48.7)$ & $153(53.5)$ & $137(44.3)$ & 0.026 \\
\hline \multicolumn{5}{|l|}{ Self-assessment of surgical predispositions: } \\
\hline No predispositions & $55(9.2)$ & $0(0.0)$ & $55(17.8)$ & $<0.001$ \\
\hline Unsatisfactory & $114(19.2)$ & $9(3.2)$ & $105(34.0)$ & $<0.001$ \\
\hline Satisfactory & $143(24.0)$ & $66(23.1)$ & $77(24.9)$ & 0.599 \\
\hline Good & $207(34.8)$ & $57(18.45)$ & $150(52.5)$ & $<0.001$ \\
\hline Very good & $76(12.8)$ & $61(21.3)$ & $15(4.9)$ & $<0.001$ \\
\hline \multicolumn{5}{|l|}{ Being able to enter and accomplish a surgical specialty: } \\
\hline Agree & $497(83.5)$ & $279(97.6)$ & $218(70.6)$ & $<0.001$ \\
\hline Disagree & $98(16.5)$ & $7(2.5)$ & $91(29.5)$ & \\
\hline Having difficulties in contact with surgical patients & $55(9.3)$ & $17(5.9)$ & $38(12.3)$ & 0.008 \\
\hline
\end{tabular}

*3.0-satisfactory, 3.5-satisfactory plus, 4.0-good, 4.5-good plus, 5.0-very good

the difference was not statistically significant. The most striking was the decline in the number of students choosing surgery between the 3rd year (62\%) and 4th year (43\%) which is shown in Fig. 1.

The grade averages did not differ significantly between students from the two groups, but students choosing surgery most often were authors of journal articles or congress presentations (54\% vs $44 \%, \mathrm{p}=0.026)$. Students interested in pursuing a surgical carrier were also more likely to assess their surgical predispositions as very good ( $21 \%$ vs $5 \%, \mathrm{p}<0.001)$. Nevertheless, most students who chose a medical specialty thought that their predispositions were good (53\%) or satisfactory (25\%). In general, most students agreed that they were able to enter and accomplish a surgical residency, but students who chose surgery were significantly more certain about it $(98 \%$ vs $71 \%, \mathrm{p}<0.001)$. Aong students who chose surgery, only $6 \%$ reported having any difficulties in contact with surgical patients. Among students who chose a medical specialty, it related to $12 \%$ of them ( $\mathrm{p}=0.008)$ (Tab. II.).

While most of the surveyed found surgery interesting (30\%) or very interesting (29\%), only $3 \%$ of students assessed surgical education quality as very good and $19 \%$ as good. $32 \%$ described it as unsatisfactory and $17 \%$ as poor. Students who considered it poor were more likely to choose a non-surgical specialty (1\% vs $16 \%$, $\mathrm{p}<0.001)$. There were no statistically significant differences between the availability of forms of surgical training in the curricula of students choosing surgical and non-surgical specialties. They also had equal access to extracurricular activities. However, students who decided to choose a surgical specialty performed some practical activities more often (dressing change, removing stitches, central line placement, peripheral vein cannulation, gastric tube placement or fracture management). They were also more likely to have the first contact with the operating theatre during their 1st year of medical school (61\% vs 39\%, p < 0.001) (Tab. III.).

The percentage of students who had a surgeon in the family did not differ significantly between the groups, but significantly more students choosing surgery reported having a mentor who is a surgeon ( $37 \%$ vs $14 \%, \mathrm{p}<0.001)$ and had a positive past experience with surgery ( $83 \%$ vs $52 \%, \mathrm{p}<0.001)$ (Tab. III.).

\section{Factors influencing the decision to enter a surgical specialty}

Students' opinions on the surgeon's lifestyle issues is showed in Fig. 2. Factors described as encouraging by most of the surveyed were: the ability to observe quick effects of treatment (86\%), work 
Tab. III. Comparison of medical education issues and experience with the surgical environment between groups of students based on career choice.

\begin{tabular}{|c|c|c|c|c|}
\hline & $\begin{array}{l}\text { ALL SUBJECTS } \\
\mathrm{N}=595\end{array}$ & $\begin{array}{l}\text { CHOOSINC A SURGICAL SPECIALTY } \\
\mathrm{N}=\mathbf{2 8 6}(\mathbf{4 8 . 0 7 \% )}\end{array}$ & $\begin{array}{l}\text { CHOOSING A MEDICAL SPECIALTY } \\
\mathrm{N}=309(51.93 \%)\end{array}$ & PVALUE \\
\hline \multicolumn{5}{|l|}{ 1. Opinion on surgical education quality: } \\
\hline Very good & $17(2.9)$ & $8(2.8)$ & $9(2.8)$ & 0.933 \\
\hline Good & $111(18.7)$ & $59(20.6)$ & $52(16.8)$ & 0.234 \\
\hline Satisfactory & $179(30.1)$ & $86(30.1)$ & $93(30.1)$ & 0.994 \\
\hline Unsatisfactory & $189(31.8)$ & $98(34.3)$ & $91(29.5)$ & 0.207 \\
\hline Poor & $99(16.6)$ & $35(12.2)$ & $64(20.7)$ & 0.006 \\
\hline \multicolumn{5}{|l|}{ 2. Interest in surgery as a field of study: } \\
\hline Very interesting & $173(29.1)$ & $135(47.2)$ & $38(12.3)$ & $<0.001$ \\
\hline Interesting & $179(30.1)$ & $108(37.8)$ & $71(23.0)$ & $<0.001$ \\
\hline Averagely interesting & $111(18.7)$ & $33(11.5)$ & $78(25.2)$ & $<0.001$ \\
\hline Slightly interesting & $81(13.6)$ & $7(2.5)$ & $74(24.0)$ & $<0.001$ \\
\hline Not interesting & $51(8.6)$ & $3(1.1)$ & $48(15.5)$ & $<0.001$ \\
\hline \multicolumn{5}{|l|}{ Forms of surgical training contained within the curriculum: } \\
\hline 1. Suturing on a training kit or animal tissues & $446(75.0)$ & $220(76.9)$ & $226(73.1)$ & 0.287 \\
\hline 2. Training on laparoscopic simulator & $216(36.3)$ & $105(36.7)$ & $111(35.9)$ & 0.841 \\
\hline 3. Wound management course & $191(32.1)$ & $97(33.9)$ & $94(30.4)$ & 0.362 \\
\hline 4. Fractures management course & $171(28.7)$ & $87(30.4)$ & $84(27.2)$ & 0.384 \\
\hline 5. Assisting at surgical operations & $353(59.3)$ & $173(60.5)$ & $180(58.3)$ & 0.579 \\
\hline \multicolumn{5}{|l|}{ Access to extracurricular activities: } \\
\hline 1. Taking part in surgical duties & $502(84.4)$ & $243(85.0)$ & $259(83.8)$ & 0.700 \\
\hline 2. Practical training in students' scientific groups & $438(73.6)$ & $220(76.9)$ & $218(70.6)$ & 0.078 \\
\hline $\begin{array}{l}\text { 3. Workshops organized by student societies or taking } \\
\text { place at medical conferences }\end{array}$ & $494(83.0)$ & $234(81.8)$ & $260(84.1)$ & 0.451 \\
\hline 4. Assisting at surgical operations & $393(66.1)$ & $197(68.9)$ & $196(63.4)$ & 0.161 \\
\hline \multicolumn{5}{|c|}{ Procedures performed during surgical rotations or extracurricular activities: } \\
\hline 1. Dressing change & $358(60.2)$ & $190(66.4)$ & $168(54.4)$ & 0.003 \\
\hline 2. Removing stitches & $367(61.7)$ & $201(70.3)$ & $166(53.7)$ & $<0.001$ \\
\hline 3. Surgical drains removal & $195(32.8)$ & $110(38.5)$ & $85(27.5)$ & 0.005 \\
\hline 4. Urinary catheterization & $224(37.6)$ & $117(40.9)$ & $107(34.6)$ & 0.114 \\
\hline 5. Central line placement & $21(3.5)$ & $17(5.9)$ & $4(1.3)$ & 0.002 \\
\hline 6. Cannulation of peripheral veins & $253(45.5)$ & $134(46.9)$ & $119(38.5)$ & 0.040 \\
\hline 7. Wound suturing & $232(39.0)$ & $156(54.6)$ & $76(24.6)$ & $<0.001$ \\
\hline 8. Gastric tube placement & $31(5.2)$ & $20(7.0)$ & $11(3.6)$ & 0.060 \\
\hline 9. Tracheal intubation & $103(17.3)$ & $53(18.5)$ & $50(16.2)$ & 0.449 \\
\hline 10. Fracture management & $86(14.5)$ & $54(18.9)$ & $32(10.4)$ & 0.003 \\
\hline \multicolumn{5}{|l|}{ 1. First contact with the operating theatre (year of study): } \\
\hline I & $246(41.3)$ & $150(61.0)$ & $96(39.0)$ & $<0.001$ \\
\hline II & $67(11.2)$ & $36(12.6)$ & $31(46.3)$ & $<0.001$ \\
\hline III & $217(36.5)$ & $78(27.3)$ & $139(45.0)$ & 0.325 \\
\hline IV & $64(10.8)$ & $22(7.7)$ & $42(13.6)$ & $<0.001$ \\
\hline V & $1(0.2)$ & $0(0.0)$ & $1(0.3)$ & 0.020 \\
\hline 2. Having a surgeon in the family & $86(14.5)$ & $48(16.8)$ & $38(12.3)$ & 0.120 \\
\hline 3. Having a mentor who is a surgeon & $148(24.9)$ & $105(36.7)$ & $43(13.9)$ & $<0.001$ \\
\hline 4. Positive past experience with the surgical environment & $399(67.1)$ & $237(82.9)$ & $162(52.4)$ & $<0.001$ \\
\hline
\end{tabular}

satisfaction (83\%), using manual skills (67\%) and prestige of the specialty (55\%). The most discouraging were: working in standing position (82\%), work-life balance (73\%), stress level (66\%) and working hours (64\%).
Most students (64\%) were discouraged from pursuing a surgical career by others. This was most often impacted by internal medicine specialists (47\%), other medical students (40\%) and surgeons themselves (28\%) (Fig. 3.). 
Tab. IV. The risk factors of resigning from pursuing a surgical specialty during studies - univariate logistic regression analysis.

\begin{tabular}{|c|c|c|c|c|}
\hline \multirow{2}{*}{$\begin{array}{l}\text { RISK FACTOR } \\
\text { Slight or no interest in surgery as a field of study }\end{array}$} & \multirow{2}{*}{$\begin{array}{l}\text { ODDS RATIO (OR) } \\
28.66\end{array}$} & \multicolumn{2}{|c|}{ CONFIDENCE INTERVAL $(95 \% \mathrm{Cl})$} & \multirow{2}{*}{$\begin{array}{l}\text { PVALUE } \\
<0.001\end{array}$} \\
\hline & & 8.67 & 94.73 & \\
\hline Feeling unable to enter and accomplish surgical specialty training & 22.54 & 5.24 & 96.95 & $<0.001$ \\
\hline Negative past experience with the surgical environment & 4.32 & 2.67 & 6.97 & $<0.001$ \\
\hline Not having a surgeon as a mentor & 3.58 & 2.14 & 6.00 & $<0.001$ \\
\hline Self-assessment of surgical predispositions as unsatisfactory & 2.87 & 7.75 & 40.31 & $<0.001$ \\
\hline Being discouraged by the partner & 2.64 & 1.20 & 5.81 & 0.016 \\
\hline First contact with the operating theatre $>$ II year of study & 2.28 & 1.49 & 3.48 & $<0.001$ \\
\hline No authorship of journal articles or congress presentations & 1.76 & 1.16 & 2.67 & 0.008 \\
\hline Lower number of practical procedures performed (continuous variable) & 1.18 & 1.07 & 1.29 & 0.001 \\
\hline Female gender & 1.58 & 1.01 & 2.45 & 0.043 \\
\hline Age ( continuous variable) & 1.05 & 0.93 & 1.18 & 0.414 \\
\hline Considering surgical education quality as poor & 1.78 & 0.98 & 3.26 & 0.060 \\
\hline Year of study >II & 1.88 & 1.00 & 3.53 & 0.051 \\
\hline Having no surgeon in the family & 1.36 & 0.78 & 2.38 & 0.280 \\
\hline Having difficulties in contact with surgical patients & 1.18 & 0.52 & 2.63 & 0.695 \\
\hline Experienced negative comments regarding gender & 0.85 & 0.56 & 1.29 & 0.449 \\
\hline Being discouraged by mother & 0.88 & 0.51 & 1.51 & 0.644 \\
\hline Being discouraged by father & 1.87 & 0.98 & 3.57 & 0.056 \\
\hline Being discouraged by friends (not medical students) & 0.82 & 0.47 & 1.43 & 0.482 \\
\hline Being discouraged by other medical students & 0.96 & 0.60 & 1.56 & 0.885 \\
\hline Being discouraged by internal medicine specialists & 0.93 & 0.61 & 1.41 & 0.734 \\
\hline Being discouraged by surgeons & 1.25 & 0.82 & 1.88 & 0.299 \\
\hline
\end{tabular}

384 students (64.5\%) were determined to pursue a surgical specialty at some point of their study period. 149 of them (38.8\%) changed their mind in subsequent years. To identify the risk factors for resigning from a surgical career, the logistic regression analysis was performed. In the univariate logistic regression analysis, the risk factors for resigning from a surgical specialty included: slight or no interest in surgery as a field of study $(\mathrm{OR}=28.7)$, feeling unable to enter and accomplish a surgical specialty $(O R=22.5)$, a negative past experience with the surgical environment $(\mathrm{OR}=4.3)$, not having a surgeon as a mentor $(\mathrm{OR}=3.6)$, self-assessment of surgical predispositions as unsatisfactory $(\mathrm{OR}=2.9)$, being discouraged by the partner $(O R=2.6)$, first contact with the operating theatre $>2$ nd year of study $(\mathrm{OR}=2.3)$, no authorship of journal articles or congress presentations ( $\mathrm{OR}=1.8)$, a lower number of practical procedures performed $(\mathrm{OR}=1.2)$ and female gender $(\mathrm{OR}=1.6)$. In the multivariate logistic regression analysis slight or no interest in surgery as a field of study $(O R=20.6)$, self-assessment of surgical predispositions as unsatisfactory $(\mathrm{OR}=14.3)$, feeling unable to enter and accomplish a surgical specialty $(\mathrm{OR}=5.2)$, being discouraged by the partner $(\mathrm{OR}=3.4)$, a negative past experience with the surgical environment $(\mathrm{OR}=3.2)$, not having a surgeon as a mentor $(\mathrm{OR}=2.6)$, no authorship of journal articles or congress presentations $(\mathrm{OR}=1.9)$ and first contact with the operating theatre $>2$ nd year of study $(\mathrm{OR}=1.90)$ were found to be the independent risk factors for abandoning a surgical career.

\section{DISCUSSION}

This study was developed to assess the level of interest in pursuing a surgical career by students and to find out which factors influence their decisions. To the best of our knowledge, it is a first survey study on this matter relating to the population of Polish medical students.

Almost half of the respondents, (48\%) declared willingness to start surgical residency after medical school. However, the percentage of students who considered surgical specialties at some point of the study period was even higher and reached $65 \%$. In other questionnaire studies, the percentage of students choosing surgery was in general lower and varied from 14\% reported in Germany, $20 \%$ in Poland and UK, 30\% in France, 19-30\% in the USA up to $20-60 \%$ in Canada [15-23]. The wide range of values might have occurred as a result of differences in the inclusion criteria (e.g. only students from final years of study), different definitions of surgical specialty or due to the high dynamics of changes in the students' choices over the years. First of all, however, it is difficult to compare such results, as there are many fundamental differences in the organization of the healthcare system and medical training between different countries. As our survey was distributed electronically, it is also possible that the students interested in surgery were more willing to complete the survey, which might result in their overrepresentation in the study population.

Alongside cultural changes, the number of women entering medical schools is increasing steadily and it is believed that this gender shift has reduced the number of students applying to surgical programs [17]. In general, women are believed to be less willing to pursue surgical careers [24]. The most commonly discussed reasons are lifestyle issues such as difficulties in managing pregnancy and maternity in such a workplace or unfavorable work-life balance, but, unfortunately, gender stereotypes still seem to play an important role in this matter $[18,20,25-26]$. We reported that $76 \%$ of 
Tab. V. The risk factors of resigning from pursuing a surgical specialty during studies - multivariate logistic regression analysis.

\begin{tabular}{|c|c|c|c|c|}
\hline \multirow{2}{*}{$\begin{array}{l}\text { RISK FACTOR } \\
\text { Slight or no interest in surgery as a field of study }\end{array}$} & \multirow{2}{*}{$\begin{array}{l}\text { ODDS RATIO (OR) } \\
20.56\end{array}$} & \multicolumn{2}{|c|}{ CONFIDENCE INTERVAL $(95 \% \mathrm{Cl})$} & \multirow{2}{*}{$\begin{array}{l}\text { PVALUE } \\
<0.001\end{array}$} \\
\hline & & 5.69 & 74.29 & \\
\hline Self-assessment of surgical predispositions as unsatisfactory & 14.28 & 5.60 & 36.38 & $<0.001$ \\
\hline Feeling unable to enter and accomplish a surgical specialty training & 5.17 & 1.07 & 25.09 & 0.042 \\
\hline Being discouraged by the partner & 3.36 & 1.28 & 8.82 & 0.014 \\
\hline Negative past experience with the surgical environment & 3.21 & 1.76 & 5.86 & $<0.001$ \\
\hline Not having a surgeon as a mentor & 2.60 & 1.35 & 5.01 & 0.004 \\
\hline No authorship of journal articles or congress presentations & 1.91 & 1.09 & 3.35 & 0.024 \\
\hline First contact with the operating theatre $>$ II year of study & 1.90 & 1.09 & 3.32 & 0.024 \\
\hline
\end{tabular}

female students experienced unpleasant comments in the context of considering a surgical profession as women and $75 \%$ were discouraged from pursuing a surgical career because of their gender.

What seems to be most appealing for medical students in the surgeons' lifestyle and way of working in our study was the level of work satisfaction, the ability to observe quick effects of treatment, using manual skills and the prestige of surgical profession. These results are consistent with other reports, where similar encouraging factors were identified [18-19, 27]. While intellectual challenges and research opportunities were described as most important by several authors, these factors were found encouraging by no more than $43 \%$ of students included in our study [21, 27-28]. In our survey, $39 \%$ of students primarily interested in surgery changed their mind during the study period. Reports from different academic centers discussed over multiple factors contributing to this problem, presenting lifestyle issues, such as working long hours and unfavorable work-life balance, were regarded as the most important $[3,14-16,29]$. This data is consistent with our results, as we found work-life balance and stress level to be discouraging for the majority of students. The general opinion that surgery is more demanding and time-consuming than other medical specialties may also lead to the situation when this career path is disadvised by partners of medical students, which, in our study, was found to be a powerful risk factor of resigning from surgery $(\mathrm{OR}=3.36)(\mathrm{Tab} . \mathrm{V}$.).

In the logistic regression analysis we found no or slight interest in surgery as a field of study to be the most important independent risk factor of resigning from surgery $(O R=20.6)$. Surprising as it may seem, students in Poland usually start their surgery course during the 3rd academic year and only then are they able to confront their ideas of surgery with reality. This appears to be in line with the fact that in our study we found a $31 \%$ decrease in the percentage of individuals declaring willingness to choose a surgical specialty between 3rd and 4th year students (Fig. 1.). During surgical rotations, students have the opportunity to observe surgeons at work and to become a part of the surgical team. Even though such an experience was assessed as positive by most students included in our study (67\%), the lack of such an impression was a risk factor for giving up on surgery $(\mathrm{OR}=3.2)$. The literature shows that a more extensive experience and an early first contact with the surgical profession may increase the level of interest in pursuing a surgical career [1,30-32]. Students who are highly interested in surgery are also more willing to search for the opportunity to observe or assist in surgical procedures before staring their mandatory surgical course [33-34]. In our study, the first contact with the operating theatre after the 2nd year was found to be an independent risk factor of resigning from surgery $(\mathrm{OR}=1.9)$.
While using manual skills was considered encouraging for most e respondents (67\%), self-assessment of surgical predispositions as unsatisfactory $(\mathrm{OR}=14.3)$ and the feeling of being unable to enroll to and accomplish surgical specialty training $(\mathrm{OR}=5.2)$ were one of the most important independent risk factors for resigning from surgery. Although the perception of own characteristics is always affected by the subjectivity bias, creating an environment in which students can discern their talents seems to be a matter of great importance. Unfortunately, only $22 \%$ of students included in our study found surgical education to be very good or good and as much as $49 \%$ assessed it as unsatisfactory or poor. What is more, only $37 \%$ of students who decided to pursue a surgical career reported having a mentor. The important role of such role models was widely described in the literature and also confirmed by our results (Tab. V.). Therefore, it seems essential for surgeons to pay more attention to students who show a certain interest in surgery. Instead of disadvising a surgical career, they should look for talented students and teach them in a mentor-trainee relationship [17, 35-38].

\section{STRENGTHS AND LIMITATIONS}

Certainly, our study has some limitations. The study population was relatively small and although the survey included various items, some important factors might be missing. What is more, students from all years were included, hence we do not know their ultimate career choices yet. The fact that the questionnaire was distributed as an online survey might also lead to a selection bias, causing students who were not interested in surgery to be less likely to be included.

We are aware that while analyzing the situation of declining interest in surgical training, not only discouraging but also encouraging factors should have been addressed. However, for such analysis, the number of students primarily uninterested in surgery, who changed their mind during the study period, was too small to create a statistically significant sample size.

After all, it is the first study investigating the problem of the decreasing level of interest in pursuing a surgical specialty amongst medical students in Poland. By using different types of questions and applying logistic regression analysis, we aimed to present a complex and complete analysis of the problem.

\section{CONCLUSIONS}

Our study revealed that fewer than half of the surveyed Polish medical students were willing to consider a surgical specialty as 
a future career. Although most of them were interested in pursuing surgery at some time during their education, the popularity of this carrier path appeared to decrease across subsequent years of study.

Data suggest that the lack of interest in surgery and concerns relating to the training program (feeling unable to accomplish a surgical specialty training, self-assessment of manual dexterity as unsatisfactory) were most discouraging. Medical students were also concerned with lifestyle issues including unfavorable work-life balance and working hours. Moreover, regardless of the fact that currently the majority of medical students in Poland are female, they seemed to be less interested in pursuing surgical carriers than male students. Referring to our results, most women experienced negative comments regarding their gender and they were often disadvised from undertaking surgical residency training. On the other hand, most students seemed to discern the pros of working as a surgeon such as the ability to observe quick effects of treatment, work satisfaction, using manual skills and prestige of the specialty. To change the worrying trend and engage students in the field of surgery, ed-

\section{REFERENCES}

1. Salna M., Sia T., Curtis G. et al.: Sustained Increased Entry of Medical Students into Surgical Careers: A Student-Led Approach. J Surg Educ., 2016; 73(1): 151-156.

2. Tambyraja A.L., McCrea C.A., Parks R.W.: Attitudes of medical students toward careers in general surgery. World J Surg., 2008; 32(6): 960-963.

3. National Resident Matching Program. NRMP website. Available at: http:// www.nrmp.org. Accessed November 2019.

4. CaRMS. R-1 Data and Reports. CaRMS website. Available at: https://www. carms.ca/data-reports/r1-data-reports/. Accessed November 2019.

5. Svirko E., Goldacre M.J., Lambert T.: Career choices of the United Kingdom medical graduates of 2005, 2008 and 2009: Questionnaire surveys. Med Teach., 2013; 35(5): 365-375

6. Lambert T.W., Smith F., Goldacre M.J.: Career specialty choices of UK medical graduates of 2015 compared with earlier cohorts: questionnaire surveys. Postgrad Med J., 2018; 94(1110): 191-197.

7. The Polish Chamber of Physicians and Dentists.: Zestawienie liczbowe lekarzy i lekarzy dentystów wg dziedziny i stopnia specjalizacji z uwzględnieniem podziału na lekarzy wykonujących i nie wykonujących zawodu. NIL website. Available at: https://www.nil.org.pl/rejestry/centralny-rejestr-lekarzy/informacje-statystyczne. Accessed November 2019.

8. Baliński P., Krajewski R.: Lekarze i lekarze dentyści w Polsce - charakterystyka demograficzna. Stan w dniu 31.12.2017 r. The Polish Chamber of Physicians and Dentists, 2018. Available at: https://e-isbn.pl/IsbnWeb/record/show_cover.pdf?picture_id=35229 Accessed November 2019.

9. Krajewski R.: Lekarze specjaliści i lekarze dentyści specjaliści w roku 2015. Gazeta Lekarska, 2015; 6: 46-47.

10. Eurostat.: Physicians by medical speciality. Eurostat website. Available at: https://ec.europa.eu/eurostat/web/health/data Accessed November 2019.

11. Whittaker L.D., Estes N.C., Ash J. et. al.: The value of resident teaching to improve student perceptions of surgery clerkships and surgical career choices. Am J Surg., 2006; 191(3): 320-324.

12. Richardson J.D.: General Surgeon Shortage in the United States: Fact or Fiction, Causes and Consequences. Soc Work Public Health., 2011; 26(5): 513-523.

13. Bland K.I., Isaacs G.: Contemporary Trends in Student Selection of Medical Specialties. Arch Surg., 2002; 137(3): 259-267.

14. Peel J.K., Schlachta C.M., Alkhamesi N.A.: A systematic review of the factors affecting choice of surgery as a career. Can J Surg., 2018; 61(1): 58-67.

15. Kleinert R., Fuchs C., Romotzky V. et al.: Generation Y and surgical residency - Passing the baton or the end of the world as we know it? Results from a survey among medical students in Germany. PLoS One., 2017; 12(11): 1-11.

16. Rogers M.E., Creed P.A., Searle J.: Why are junior doctors deterred from choosing a surgical career?, Australian Health Review., 2012; 36: 191-196.

17. Erzurum V.Z., Obermeyer R.J., Fecher A. et. al.: What influences medical students' choice of surgical careers. Surgery., 2000; 128(2): 253-256. ucators should become aware of these views. While the lack of exposure to the surgical environment in preclinical years, having no mentor and the lack of scientific achievements were found to be the risk factors of giving up on surgery, the improvement of surgical education quality (which was assessed as unsatisfactory by a great number of the students), providing positive role models and an early involvement in the operating room seem to be essential. Arousing the interest of student groups and structured research opportunities are also needed. What is more, efforts should be made to promote interest in surgery as a career for women and to provide a more flexible approach to surgical training.

In this study, we have laid out groundwork that may be an important component in understanding and also counteracting the decreasing interest in surgery in Poland, thereby meeting our population's need for surgical procedures. However, multi-institutional, well-designed studies using validated questionnaires are needed to provide a better understanding of the reasons for the declining number of applications into surgical residency programs.

18. Scott I.M., Matejcek A.N., Gowans M.C. et. al.: Choosing a career in surgery: Factors that influence Canadian medical students' interest in pursuing a surgical career. Can J Surg., 2008; 51(5): 371-377.

19. Berger A.P., Giacalone J.C., Barlow P. et. al.: Choosing surgery as a career: Early results of a longitudinal study of medical students. Surgery., 2017; 161(6): 1683-1689.

20. Goldacre M.J., Goldacre R., Lambert T.W.: Doctors who considered but did not pursue specific clinical specialties as careers: Questionnaire surveys. J R Soc Med., 2012; 105(4): 166-176.

21. Glynn R.W., Kerin M.J.: Factors influencing medical students and junior doctors in choosing a career in surgery. Surgeon., 2010; 8(4): 187-191.

22. Lefèvre J.H., Karila L., Kerneis S. et. al.: Motivation of French medical students to pursue surgical careers: Results of national survey of 1742 students. J Visc Surg., 2010; 147(3): e181-6.

23. Rudnicki J., Zyśko D., Kozłowski D. et. al.: The Choice of Surgical Specialization by Medical Students and Their Syncopal History. PLoS One., 2013; 8(1): 4-11.

24. Coulston C., Vollmer-Conna U., Malhi G.: Female medical students: who might make the cut? Psychiatry Res., 2012; 200(2-3): 457-463.

25. Stratton T.D., McLaughlin M.A., Witte F.M.: Does students' exposure to gender discrimination and sexual harassment in medical school affect specialty choice and residency program selection? Acad Med., 2005; 80(4): 400-408.

26. Mayer K.L., Perez R.V., Ho H.S.: Factors affecting choice of surgical residency training program. J Surg Res., 2001; 98(2): 71-75.

27. Brundage S.I., Lucci A., Miller C.C. et. al.: Potential targets to encourage a surgical career. J Am Coll Surg., 2005; 200(6): 946-953.

28. Corrigan M.A., Shields C.J., Redmond H.P.: Factors influencing surgical career choices and advancement in Ireland and Britain. World J Surg., 2007; 31(10): 1921-1929.

29. Lambert T.W., Davidson J.M., Evans J. et. al.: Doctors' reasons for rejecting initial choices of specialties as long-term careers. Med Educ., 2003; 37(4): 312-318.

30. O'Herrin J.K., Lewis B.J., Rikkers L.F. et. al.: Why do students choose careers in surgery? J Surg Res., 2004; 119(2): 124-129.

31. Are C., Stoddard H.A., Northam L.C. et. al.: An Experience in Surgical Anatomy to Provide First-Year Medical Students with an Early Exposure to General Surgery: A Pilot Study. J Surg Educ., 2009; 66(4): 186-189.

32. Marshall D.C., Salciccioli J.D., Walton S.J. et. al.: Medical Student Experience in Surgery Influences Their Career Choices: A Systematic Review of the Literature. J Surg Educ., 2015; 72(3): 438-445.

33. Goldin S.B., Schnaus M.J., Horn G. et.al.: Surgical interest and surgical match for third-year students: Results of a prospective multivariate longitudinal cohort study. J Am Coll Surg., 2012; 215(5): 599-606.

34. Hochberg M.S., Billig J., Berman R.S. et. al.: When surgeons decide to become surgeons: New opportunities for surgical education. Am J Surg., 2014; 207(2): 194-200. 
35. Healy N.A., Cantillon P., Malone C. et.al.: Role models and mentors in surgery Am J Surg., 2012; 204(2): 256-261.

36. Hossain N., Hossain T.: Motivating factors and barriers towards choosing a career in general surgery: a review of the literature. Int Surg J., 2015; 2(2): 1.
37. Gelfand D.V., Podnos Y.D., Wilson S.E. et. al.: Choosing General Surgery. Arch Surg, 2002; 137(8): 53-56.

38. Quillin R.C., Pritts T.A., Davis B.R. et. al.: Surgeons underestimate their influence on medical students entering surgery. J Surg Res, 2012; 177(2): 201-206.

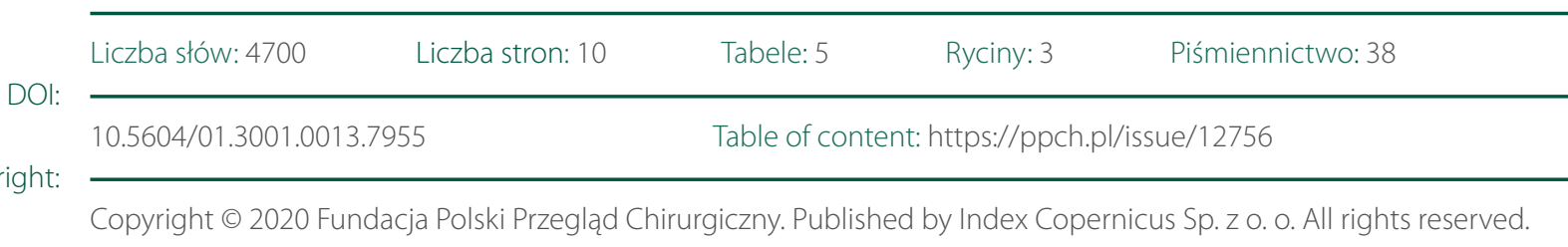

Competing interests:

The authors declare that they have no competing interests.

(6)

The content of the journal „Polish Journal of Surgery" is circulated on the basis of the Open Access which means free and limitless access to scientific data.

\section{(c) (1) (2)(2)}

This material is available under the Creative Commons - Attribution 4.0 GB. The full terms of this license are available on: http://creativecommons.org/licenses/by-nc-sa/4.0/legalcode

Corresponding author:

Michał Romaniszyn, PhD; Department of Medical Didactics, Jagiellonian University Medical College, Poland; św. Łazarza Street 16, 31-530 Krakow, Poland; E-mail: m.romaniszyn@mp.pl

Cite this article as:

Skorus U., Karpinska I.A., Kominko A., Romaniszyn M.: Why do Polish medical students resign from pursuing surgical careers? A survey study; Pol Przegl Chir 2020: 92 (2): 12-21 
